\title{
ELECTRON BEAM WELDING OF MEDIUM-PRESSURE CHAMBER OF GAS TURBINE ENGINE
}

\author{
V.M. NESTERENKOV ${ }^{1}$, L.A. KRAVCHUK ${ }^{1}$, Yu.A. ARKHANGELSKY ${ }^{1}$, \\ I.A. PETRIK ${ }^{2}$ and Yu.A. MARCHENKO ${ }^{2}$ \\ ${ }^{1}$ E.O. Paton Electric Welding Institute, NASU \\ 11 Bozhenko Str., 03680, Kiev, Ukraine. E-mail: office@paton.kiev.ua \\ ${ }^{2}$ Company «Motor-Sich» \\ 15 Motorostroiteli Ave., 69068, Zaporozhie, Ukraine. E-mail: motor@motorsich.com
}

\begin{abstract}
Investigations were performed in order to develop the technology of manufacturing all-welded outer part of front case of GTE medium-pressure chamber, and schemes of welding the inner and outer butt welds of posts were selected, providing defect-free formation of face and root weld beads at through-thickness penetration of cast titanium $\alpha$-alloy VT5L of 5-26 mm thickness in one pass. System of computer control of the process of EBW in UL-209M machine allows performing in one process cycle cleaning of the butt vicinity from remains of contamination and oxides, using low-power electron beam focused on the metal surface, as well as spot, short and continuous tack welds. Rotators with vertical and horizontal axes of rotation are provided for positioning, fixing and rotation of the item relative to electron beam gun. Programs for EBW given in the form of tables, assign the values of coordinates of points of each path section, to which it is necessary to move, values of welding and focusing currents, process scan amplitudes, as well as speed of displacement in a given section. At constant welding speed $12 \mathrm{~mm} / \mathrm{s}$, values of welding current and focusing current in the transition points of the change of working distance and thickness of edges being welded were varied by a linear law, that ensured formation of the weld face and root beads without undercuts or depressions along the entire butt length. 15 Ref., 7 Figures.
\end{abstract}

$\boldsymbol{K} \boldsymbol{e} \boldsymbol{y} \boldsymbol{w} \boldsymbol{o r d} \boldsymbol{s}:$ electron beam welding, electron beam, through-thickness penetration, weld face and root beads, variable thickness, welding scheme, porosity, macrostructure, computer control, videocontrol device, welding program

Development of design solutions and technological processes in manufacture of gas turbine engines (GTE) in aircraft industry showed that improvement of adaptability to fabrication of structures, coefficient of metal utilization, lowering of labour and power consumption of the items are possible through application of welded structures.

It is known that EBW is extensively applied in local and foreign aircraft and space industry in manufacture of aircraft engine elements [1-4].

This work gives the sequence and content of process operations for manufacturing the allwelded outer part of front case of medium-pressure chamber (MPC), consisting of posts and vanes, by EBW. In keeping with technical requirements, vanes and posts from cast titanium alloy VT5L after assembly in a rigid assemblywelding fixture should be welded to each other along the inner and outer shroud platforms, ensuring the required relative position of the vanes and posts with respect to the engine axis ( $\mathrm{Fi}^{-}$ gure 1). Number of vanes and posts is $34 \mathrm{pcs}$, and total number of welds along the inner and outer diameters is 68, MPC front case outer diameter does not exceed $1390 \mathrm{~mm}$ in assemblywelding fixture. EBW process should provide complete penetration of edges of variable crosssection along the entire butt length with guaranteed formation of weld face and root beads without undercuts or depressions, as well as protection of vane airfoil and adjacent surfaces from damage by the electron beam.

Cast medium-strength titanium $\alpha$-alloy VT5L was selected as the material for the vanes and posts. Alloy composition, according to GOST 19807-74, includes (wt.\%): 4.3-6.2. Al and $\geq 0.8$ Mo. Regulated impurities content is as follows, wt.\%:

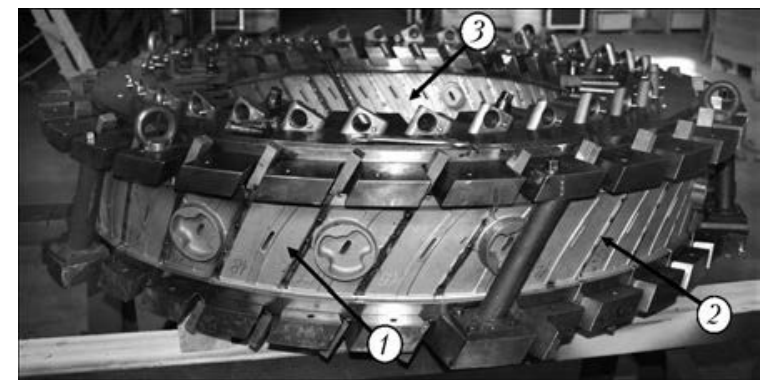

Figure 1. Appearance of outer part of MPC front case in assembly-welding fixture: 1 - posts; 2 - outer butt between posts; 3 - inner butt between posts 
$0.20\left[\mathrm{O}_{2}\right] ; 0.05\left[\mathrm{~N}_{2}\right] ; 0.015\left[\mathrm{H}_{2}\right]$. VT5L alloy is applied for parts operating at up to $350{ }^{\circ} \mathrm{C}$ temperature for a long time, and is not subjected to strengthening heat treatment.

Initial testing of the modes of VT5L alloy EBW on $100 \times 250 \mathrm{~mm}$ plates of various thickness was performed in UL-209M machine designed by PWI with computer control of all the parameters and systems. This machine is fitted with power unit based on ELA-60 / 60 and electron beam gun, moving inside the vacuum chamber along linear coordinates $X, Y, Z$, as well as rotatable around axis $Y-Y$ along $V G$ coordinate to angle of $0-90^{\circ}$. At accelerating voltage $U_{\text {acc }}=60 \mathrm{kV}$ the electron beam gun with metal tungsten cathode of $3 \mathrm{~mm}$ diameter provides electron beam current range $I_{\mathrm{b}}=0-500 \mathrm{~mA}$ and performance of beam technological scans during EBW (circle, ellipse, dash, triangle) with $0-5 \mathrm{~mm}$ amplitude. Accuracy of positioning the electron beam gun along the coordinates was not less than $0.1 \mathrm{~mm}$.

Electron beam focusing on the surface of plates being welded, alignment of electron beam with the butt, visualization of EBW process during cleaning of near-weld zone by low-power sharply focused electron beam and making short tack welds, was performed automatically by a program, using RASTR system in secondary emission image [5], which ensured alignment accuracy of not less than $0.1 \mathrm{~mm}$ and 5 times increase of the object of observation. Control of focusing by image sharpness on RASTR system monitor was checked visually by brightness of circular scan of electron beam of diameter $d_{\text {circ }} \approx 5 \mathrm{~mm}$ with $I_{\mathrm{b}} \approx 10 \mathrm{~mA}$ on copper plate. Discrepancy between the compared values of focusing current at working distance from gun edge to plate $l_{\text {work }}=$ $=250 \mathrm{~mm}$ was equal to $\pm 1 \mathrm{~mA}$ on the level of $I_{\mathrm{f}}=620 \mathrm{~mA}$, that is quite acceptable for practical application.

Developed computer control of UL-209M machine allows implementation of EBW program control by successive performance of the following processes [5]:

- plotting 3D virtual representation of the situation inside the vacuum chamber;

- selection of initial butt trajectory, using the constructed virtual representation;

- system training to perform displacement for following the butt trajectory.

EBW programs, presented in the form of tables, assign the values of point coordinates of each section of the path, where it is necessary to move, values of welding and focusing currents, process scan amplitudes, as well as displacement speed in this section.
Rotators with vertical and horizontal axes of rotation are envisaged in UL-209M machine for mounting, fixation and rotation of the outer part of MPC front case relative to electron beam gun. Faceplate diameter in both the rotators is equal to $1200 \mathrm{~mm}$.

Selection of relative position of electron beam and butt in welding VT5L alloy of thickness in the range of 5-26 $\mathrm{mm}$ with through-thickness penetration in one pass and defect-free formation of the face and root beads of the weld is the starting point of research. The principle of soundness of critical structures from titanium alloys in aircraft and space industry implies producing sound welded joints, formed at EBW, without pores or undercuts on both sides of the weld. Above-mentioned defects are inadmissible, as they lead to deterioration of welded joint performance. Elimination of undercuts in UL-209M machine can be achieved by repeated cosmetic pass, as well as selection of the scheme of EBW by horizontal electron beam with electron beam gun downward displacement along $Z-Z$ coordinate [6]. Horizontal position of the weld pool facilitates liquid metal degassing and its refining that, in its turn, lowers weld metal porosity and requirements to cleanliness of metal being welded.

Selection of optimum welding speed value is determined, on the one hand, by the condition of minimum intensity of hydrodynamic disturbances in the weld pool [7] and, on the other hand, by the condition of minimum weld width for reducing deformations, increasing crack resistance, and preservation of volatile alloying elements in weld metal. While the first condition requires lowering the welding speed, the second one requires its increase. Precising the value of welding speed for specific alloys and thicknesses to produce a sound welded joint plays a paramount role in development of welding technology. For UL-209M machine, allowing for thickness of welded edges of VT5L titanium alloy varying in the range of $5-26 \mathrm{~mm}$, as well as ensuring $I_{\mathrm{b}}=0-500 \mathrm{~mA}, 12 \mathrm{~mm} / \mathrm{s}$ welding speed was selected constant along the entire butt length.

Reproducibility of sound welds can be ensured due to a multitude of hardware developments, guaranteeing stabilization and repeatability of electron beam geometry [8-10]. Narrow and deep welds with parallel walls of the cast zone are produced due to application of electron beam with small $\left(\leq 5 \cdot 10^{-2} \mathrm{rad}\right)$ angles of convergence $[10,11]$, its scanning in a circular or elliptical pattern [8, 9, 12]. We applied a circular scan, which ensured reproducibility of weld formation 
at inclined butt of the posts relative to the direction of downward displacement of electron beam gun along coordinate $Z-Z$.

Porosity is the main defect of weld metal at EBW of titanium and its alloys. To prevent pore formation, it is necessary to ensure removal of adsorbed moisture and oil films from the surface of edges being welded, as well as create conditions for maximum degassing of the weld pool. Cleaning of the butt vicinity from remains of contaminations and oxides using electron beam focused on the metal surface can be performed in one EBW process cycle in UL-209M machine. A pass along the entire butt length is performed in the mode of $U_{\mathrm{acc}}=60 \mathrm{kV}, I_{\mathrm{b}} \approx 10 \mathrm{~mA}, v_{\mathrm{w}}=$ $=10 \mathrm{~mm} / \mathrm{s}$ and $d_{\text {circ }} \approx 10 \mathrm{~mm} \mathrm{[5]}$.

At EBW of titanium and its alloys precise fit-up of the item for welding and strict maintenance of admissible gap dimensions between the part edges being welded are required to produce sound welds. As shown in [13], at $5 \mathrm{~mm}$ thickness of butts being welded the admissible gap value should not exceed $0.07 \mathrm{~mm}$, and $0.17 \mathrm{~mm}$ at $\delta_{\mathrm{m}}=$ $=26 \mathrm{~mm}$.

Before developing programs of EBW of inner and outer butt welds on posts from alloy VT5L measurements were taken of the thickness of edges to be welded along the length of a butt with complex contour. It was established that several characteristic thicknesses of different length are in place: for geometry of outer butt weld end face $-5,14,17 \mathrm{~mm}$; for geometry of inner butt weld end face $-5,17,19$ and $26 \mathrm{~mm}$. At optimization of the modes of EBW of the post outer butt welds by horizontal electron beam by the downward scheme, through-thickness penetration was performed on flat samples at $v_{\mathrm{w}}=$ $=12 \mathrm{~mm} / \mathrm{s}, l_{\text {work }}=250 \mathrm{~mm}$ without local beam scanning $\left(d_{\text {circ }}=0\right)$ and with circular beam scan$\operatorname{ning}\left(d_{\text {circ }}=1.2 \mathrm{~mm}\right)$ with weld face and root bead formation in one pass. For defect-free formation of the weld root bead electron beam current was set in the range of $(1.75-2) I_{0}$, where $I_{0}$ is the beam current, at which the first indications of throughthickness penetration are visible [14].

Performed metallographic analysis of welded joints of VT5L alloy with through-thickness penetration of flat samples revealed certain features. As shown in Figure 2, formation of weld face and root beads at all the available thicknesses occurs regularly along the entire length without undercuts; if required, the weld face bead is smoothed by a repeated cosmetic pass. Starting from welded edge thickness $\delta_{\mathrm{m}}=14 \mathrm{~mm}$ the weld forms with practically parallel walls of the cast zone in the case of application of a circular scan

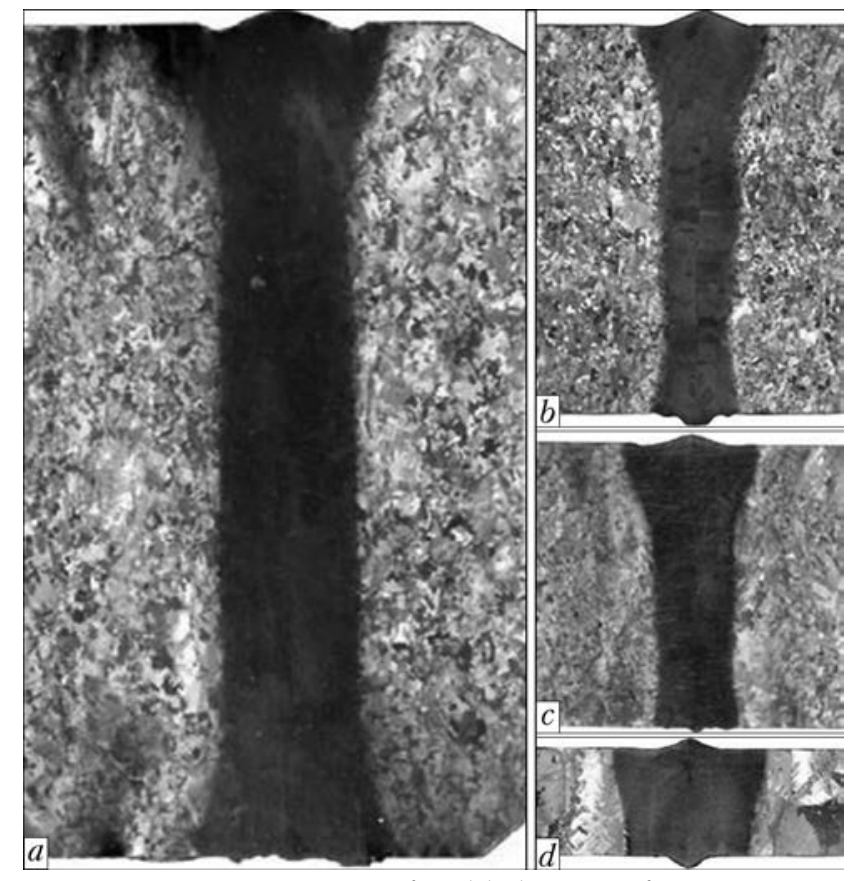

Figure 2. Macrostructure of welded joints of cast titanium alloy VT5L of different thickness, and formation of weld face and root beads in EBW with through-thickness penetration of outer butt welds of posts by horizontal electron beam: $a-\delta_{\mathrm{m}}=26 ; b-17 ; c-14 ; d-5 \mathrm{~mm}$

of the electron beam with $d_{\text {circ }}=1.2 \mathrm{~mm}$, and weld width in the root part varies in the range of 2.4-2.6 mm. Such results on penetration geometry lead to the conclusion that welding electron beam deviation from the butt to a value of $0.1 \mathrm{~mm}$ will not affect weld quality.

Derived data on welding flat samples by horizontal electron beam were applied in development of a program of welding outer butt welds on post-samples of alloy VT5L, in which the butt configuration in welding area corresponds to batch-produced parts. In the program at constant welding speed $12 \mathrm{~mm} / \mathrm{s}$, the values of welding and focusing current in the points of transition at the change of working distance and thickness of edges being welded were varied by a linear law [15].

As shown in Figure 3, the weld forms without defects along the entire butt length, and the weld root bead can be used for controlling the welding quality. The system of computer control of EBW process in UL-209M machine allows performing in one process cycle also spot, short and continuous tack welds. Spot welds on the butt of run-off tab and post are performed, in order to eliminate crater formation.

It should be noted that all the welded samples and mock-ups of items from VT5L alloy with through-thickness penetration by a horizontal electron beam have passed X-raying. No defects in the form of cavities, pores, undercuts or lacksof-fusion were found. 


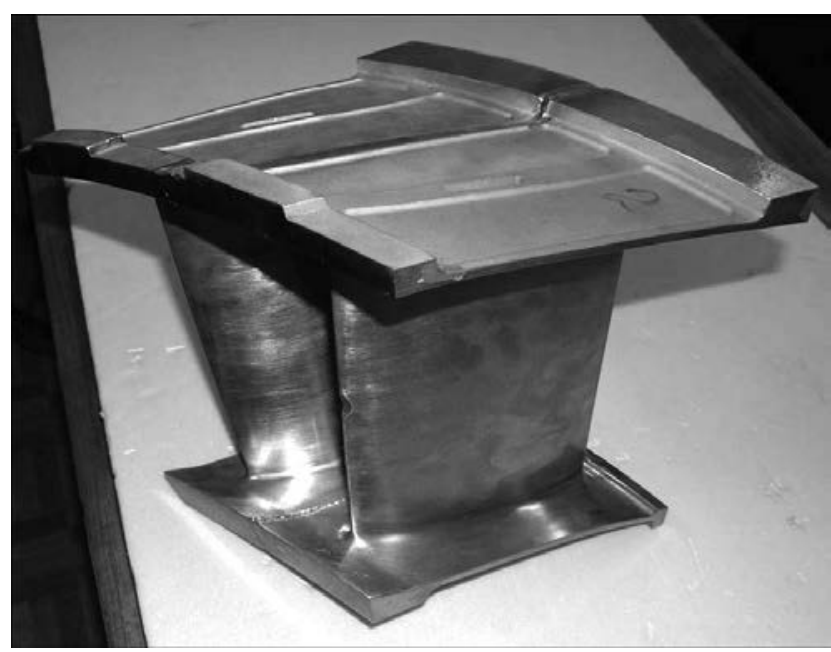

Figure 3. Appearance of weld face and root beads on postssamples in EBW of outer and inner butt welds at $U_{\text {acc }}=$ $=60 \mathrm{kV}, v_{\mathrm{w}}=12 \mathrm{~mm} / \mathrm{s}$ and $l_{\text {work }}=250 \mathrm{~mm}$

After mounting run-off tabs from titanium alloy VT5L on the inner and outer butts of the posts using argon-arc welding, the outer part of MPC front case was placed on the rotator faceplate coaxially with the vertical axis of rotation (Figure 4), electron beam gun was moved into the horizontal position $\left(V G=0^{\circ}\right)$ at distance to the item $l_{\text {work }}=250 \mathrm{~mm}$, gun axis was moved to one of the 34 butts, value of rotator coordinate $W$ was zeroed, and UL-209M machine was prepared for performance of EBW of the post outer butt welds by the program.

After achieving the working vacuum in the welding chamber and electron beam gun, RASTR video-monitoring system was used to make a new program of EBW of the first butt of the post at downward displacement of the gun along $Z-Z$ coordinate or to correct EBW program on postssamples. Trial run of the electron beam gun by the program was performed and in the case of electron beam hitting the butt along its entire length, WELDING mode was run (Figure 5).

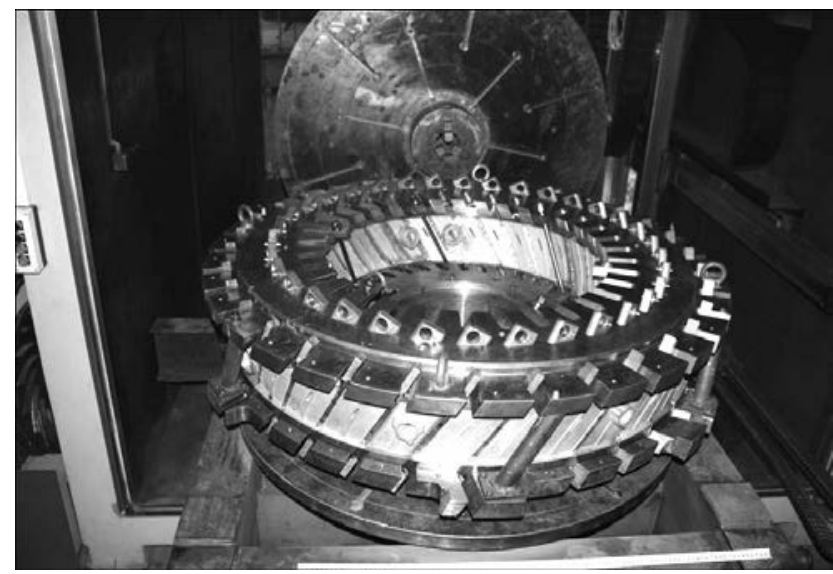

Figure 4. Appearance of outer part of MPC front case placed onto rotator with vertical axis of rotation for EBW of post outer butt welds

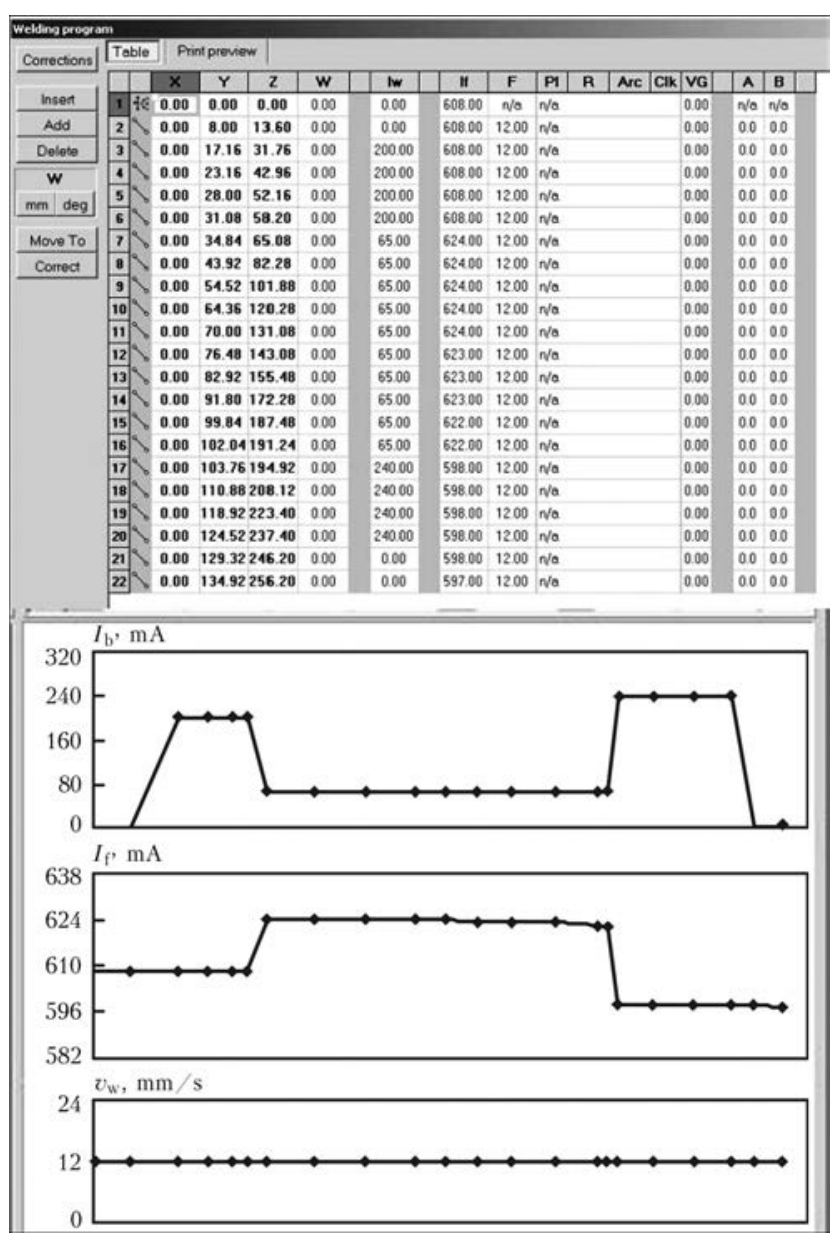

Figure 5. Program of EBW of outer butt welds of posts with computer control of displacements along coordinates $Y$ and $Z$, as well as welding $I_{\mathrm{b}}$ and focusing $I_{\mathrm{f}}$ currents and welding speed $v_{\mathrm{w}}$

Cyclogram of welding and focusing current variation with reference to specific points is given in Figure 6. After rotation of MPC front case through $180^{\circ}$ along rotator coordinate $W$, EBW of the post butt weld from the opposite side was performed. The described operational sequence is performed till the last butt weld on the posts.

Welding of outer butt welds of the posts by horizontal electron beam in a rotator with vertical axis of rotation was followed by starting the preparation for the technological process of EBW of inner butt welds. Transition to a rotator with the horizontal axis of rotation, inclination of the electron beam gun to $V G=35^{\circ}$ from the vertical and gun displacement by coordinate $X-X$ along the vacuum chamber longitudinal axis turned out to be the working variant (Figure 7). Working distance from the gun edge to the item was equal to $330 \mathrm{~mm}$. It should be noted that the sequence of operations of EBW of inner butt welds did not change, compared to welding the outer butt welds, and it was not necessary to change the value of electron beam current. 


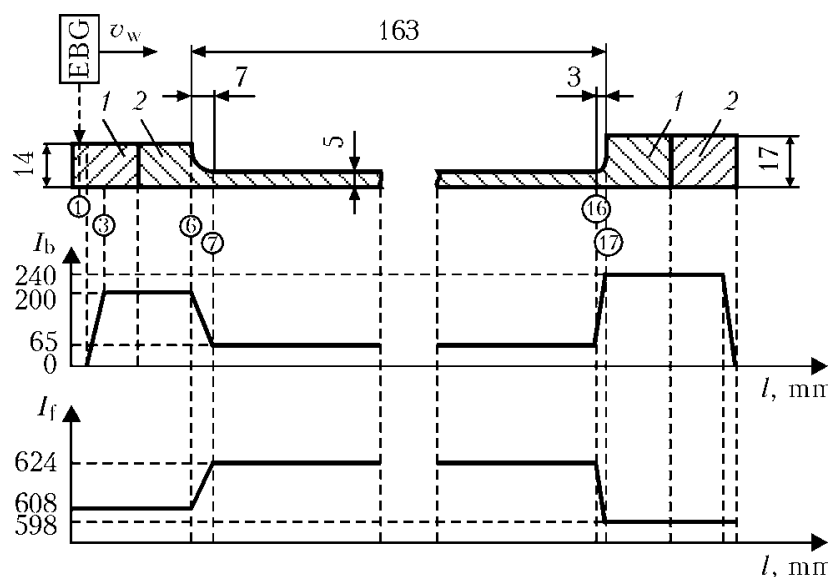

Figure 6. Cyclogram of variation of welding $I_{\mathrm{b}}$ and focusing $I_{\mathrm{f}}$ currents in EBW of outer butt welds of posts: 1 - run-off tabs; 2 - posts; (1), (3), (6), (7), (16), (17) - line numbers in EBW program table

Thus, the proposed technology of manufacturing the all-welded MPC case and the selected scheme of welding the outer and inner butt welds of the posts provide defect-free formation of the weld face and root beads at through-thickness penetration of cast titanium alloy VT5L 5$26 \mathrm{~mm}$ thick in one pass.

1. Pavlenko, V.N., Rudnev, Yu.T., Barinov, V.V. et al. (1989) Electron beam welding of GTE multisection wheel from titanium alloy. In: Abstr. of AllUnion Sci.-Techn. Conf. on Electron Beam Welding in Mechanical Engineering (Nikolaev, Ukraine, 1989), 13-14

2. Gejkin, V.A., Poklad, V.A. (2001) Welded joints in aircraft engines. Tekhnologiya Metallov, 1, 9-14.

3. Lobanov, L.M., Pivtorak, V.A., Zadery, B.A. et al (1993) Residual stresses in electron beam welded elements of gas turbine engine rotor structures. In: Proc. of Conf. on EBW, Book 2, 57-61. Moscow: TsRDZ.

4. Imamura, T. (1999) Current states and trend of applicable material technology for aerospace structure. J. JILM, 1(7), 302-309.

5. Paton, B.E., Nazarenko, O.K., Nesterenkov, V.M. et al. (2004) Computer control of electron beam welding with multi-coordinate displacements of the gun and workpiece. The Paton Welding J., 5, 2-5.

6. Kravchuk, L.A. (2010) Elimination of undercuts in EBW with complete and incomplete penetration. Ibid., 6, 22-25.

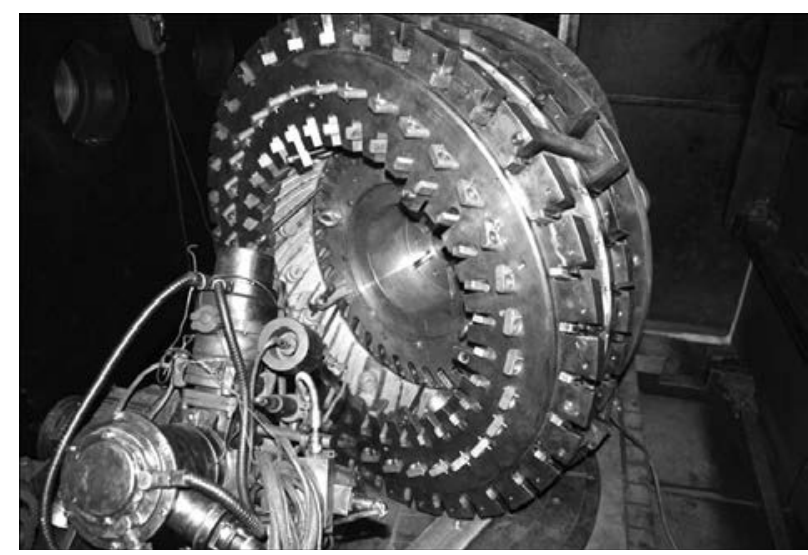

Figure 7. Appearance of outer part of MPC front case placed onto rotator with horizontal axis of rotation for EBW of post inner butt welds by electron beam gun positioned at $V G=35^{\circ}$

7. Nesterenkov, V.M. (2003) Special features of capillary waves in the vapour-gas channel in electron beam welding of thick metal. Ibid., 4, 7-12.

8. Nazarenko, O.K., Kajdalov, A.A., Kovbasenko, S.N. et al. (1987) Electron beam welding. Kiev: Naukova Dumka.

9. Blakely, P.Y., Sanderson, A. (1984) The origin and effect of magnetic fields in electron beam welding. Welding J., 1, 42-49.

10. Frits, D. (1988) Electron beam welding today. In: Proc. of Int. Conf. on Electron Beam Technologies (Varna, 31 May-4 June, 1988), 1048-1063.

11. Sayegh, G. (1986) State of the art of high energy density beam welding: Houdremont lecture. Tokyo: IIW.

12. Shida, T., Kita, H., Okamura, H. et al. Effects of welding parameters and prevention of defects in deep penetration EBW of heavy section steel. IIW Doc. $I V, 239-78$.

13. Stocker, G. (1974) Erfahrungen beim Elektronenstrahlschweissen dick wandiger Bauteile aus der Titanlegierung $\mathrm{Ti}_{6} \mathrm{Al}_{4} \mathrm{~V}$ gegliht. Schweissen und Schneiden, 3, 91-93.

14. Nudelman, Ya.B., Zadery, B.A. (1988) Weld formation in electron beam welding of titanium alloy of up to $25 \mathrm{~mm}$ thickness. Avtomatich. Svarka, 5, 29-30.

15. Anderl, P., Scheffels, W (1992) Process control for electron beam welding. Welding in the World, 5/6, $138-144$

Received 13.07.2015 